Review

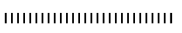

\title{
Recent Topics on Action Mechanisms of Fungicides
}

\author{
Isamu YAMAGUCHI* and Makoto FUJIMURA ${ }^{\dagger}$ \\ RIKEN Plant Science Center, 1-7-22 Suehiro, Tsurumi, Yokohama, Kanagawa 230-0045, Japan \\ ${ }^{\dagger}$ Faculty of Life Science, University of Toyo, Itakura, Oura-gun, Gunma 374-0193, Japan
}

(Received December 27, 2004)

\begin{abstract}
Plant diseases are damaging to crop production in a temperate and humid climate like that of Japan, which has resulted in the development of many excellent fungicides, but wide-spread use of site-specific fungicides can cause pathogens to develop resistance in the field. While all modern fungicides have been developed through extensive safety evaluation, there is deep public concern about their side effects on non-target organisms. Thus there is a growing interest in non-fungicidal disease-controlling agents since they are supposedly specific to target organisms and less likely to cause resistance. Two groups of non-fungicidal rice blast chemicals are currently on the market; melanin biosynthesis inhibitors (MBIs) and plant defense activators or priming effectors which induce host resistance against the pathogen's attack. Recently, field isolates resistant to MBI-D have emerged and molecular mechanisms of action/resistance are attracting interest. Complex III in the electron transport system of fungal mitochondria which contains a cytochrome $b$ with two ubiquinone binding sites, Qo and Qi, is another novel target of fungicides. Methoxyacrylate fungicides are known to block electron flow by binding to the Qo site. Resistance to Qo inhibitors has been observed in field isolates with a point mutation in the cytochrome $b$ gene (G143A). While dicarboximide fungicides have been applied to protect various crops and vegetables against gray mold and other diseases, their mechanisms of action have remained unclear for many years; recent study revealed that dicarboximides interfere with the osmotic signal transduction pathway consisting of histidine kinase and MAP kinase cascades. The mutations conferring dicarboximide resistance in the field have been identified within the histidine kinase genes in Botrytis cinerea and Alternaria alternata. Thus management strategies for fungicide resistance may become a part of registration requirements worldwide. (C) Pesticide Science Society of Japan
\end{abstract}

Keywords: melanin biosynthesis inhibitors, plant activators, methoxyacrylate fungicides, fungicide resistance, osmotic signal transduction pathway.

\section{INTRODUCTION}

The mode of action of a fungicide can be defined as the sum of factors contributing to its control of a disease. While elucidating the molecular mechanism of action is important to clarify the biochemical events occurring in the pathogen's cells and also for safety assessment of a fungicide, physicochemical properties such as solubility in water, log Pow, and stability to biotic and abiotic degradation processes are of great value in determining the actual mode of action of the fungicide in vivo.

The intrinsic activity of a fungicide is based on the specific affinity for and strength of binding to the target site, and then the activity of the target enzyme, the assembly of biochemical

\footnotetext{
* To whom correspondence should be addressed.

E-mail: yamaism@riken.jp

(C) Pesticide Science Society of Japan
}

subunits or the transduction of signals may be inhibited by the fungicide. If a fungicide binds and affects only one enzyme, the chemical is said to be a single site inhibitor. The risk of emergence of resistance is naturally higher for single site fungicides than multi-site ones. Mutations in the target gene conferring resistance can confirm the proposed biochemical action mechanism of the fungicide. The possibility of resistance is believed to be higher for inhibitors targeting the primary metabolism of pathogens than inhibitors acting on secondary metabolism. In this article, recent topics on the modes of action and mechanisms of resistance to novel fungicides are described, which will hopefully suggest the qualities that ideal fungicides should possess.

\section{NON-FUNGICIDAL CHEMICALS TO CONTROL RICE BLAST DISEASE}

\section{Melanin Biosynthesis Inhibitors}

When the rice blast pathogen Magnaporthe oryzae recognizes 
the surface characteristics of the host plants such as lipophilicity and hardness, its germinating hypha starts differentiating a special cell termed an appressorium to infect the plant. The formation of appressoria involves signal transduction and the expression of many genes. Then, appressorial cells mature by forming a layer of melanin on the innermost part of the cell wall, which affords high osmotic pressure generated inside the cell to penetrate the cuticle layer of the host plant. Thus if melanin biosynthesis is inhibited, the pathogen cannot exert its pathogenicity. In fact, melanin biosynthesis inhibitors (MBIs) are primarily not toxic to the vegetative growth of $M$. oryzae, but achieve outstanding control of the blast disease in vivo. Actually there are two types of melanin biosynthesis inhibitors; hydroxynaphthalene reductase inhibitors (MBI-R: fthalide, tricyclazole and pyroquilon) and scytalone dehydratase inhibitors (MBI-D: carpropamid, diclocymet and fenoxanil). The buff mutants of $M$. oryzae were shown to phenotypically resemble the MBI-R-treated wildtype strains and were essentially nonpathogenic to rice plant, which suggested that a melanin biosynthetic pathway is indispensable for the appressoria to obtain infectiosity. ${ }^{1)}$

Carpropamid was developed as a novel potent controlling agent against the rice blast, ${ }^{2)}$ and enzyme kinetic data showed that carpropamid is a tight-binding competitive inhibitor of scytalone dehydratase (STD), a key enzyme in the biosynthesis of melanin. Its calculated $K \mathrm{i}$ value was $140 \mathrm{pM}$, which is more than $10^{5}$ times smaller than the $K \mathrm{~m}$ for scytalone. ${ }^{3,4)}$ An X-ray analysis of the crystal structure of the STD complex with carpropamid identified interactions that determine the tight-binding ${ }^{5)}$ as shown in Fig. 1. Three types of interactions were considered important for the binding: (1) a strong hydrogen bond between N131 (Asn 131) and chlorine, (2) two hydrogen bonds mediated by water molecules (WTA) and (3) the interaction of the phenyl group of carpropamid with aromatic amino acid residues of STD. Structural data also inferred that the C-terminal region (G154-K172) is important for the enzyme function, suggesting that the region acts as a flexible lid which controls the access of substrates or inhibitors to the active site pocket. A recent study on the molecular dynamics of STD revealed that the cooperative motions of enzyme protein and hydration water molecules are important for catalysis and structural integrity. ${ }^{6}$ )

Some amino acid residues involved in the inhibitor binding were exchanged for others by site-directed mutagenesis. The Y30F, V75A, and F169A mutants still retained enzyme activity (more than $5 \%$ of original STD activity) but the $K$ i values for carpropamid significantly increased in V75A and F169A, suggesting the specific involvement of V75 and F169 of STD in carpropamid binding. The results also implied that further point mutations of V75 and F169 might produce carpropamid-resistant strains. In fact, field resistant mutants with V75M STD emerged in Saga prefecture of Japan in

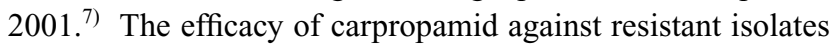
was examined and extensive monitoring of the mutant isolates was performed. ${ }^{8,9)}$ Studies on the mechanism of resistance and characterization of mutant STD proved that a single-point mutation resulted in a one-amino acid substitution (valine [GTG] 75 to methionine [ATG]: V75M) in STD. ${ }^{10,11)} \mathrm{Re}-$ cently, new STD-inhibitors such as diclocymet ${ }^{12)}$ and fenoxanil $^{13)}$ have been developed and registered as anti-blast chemi-

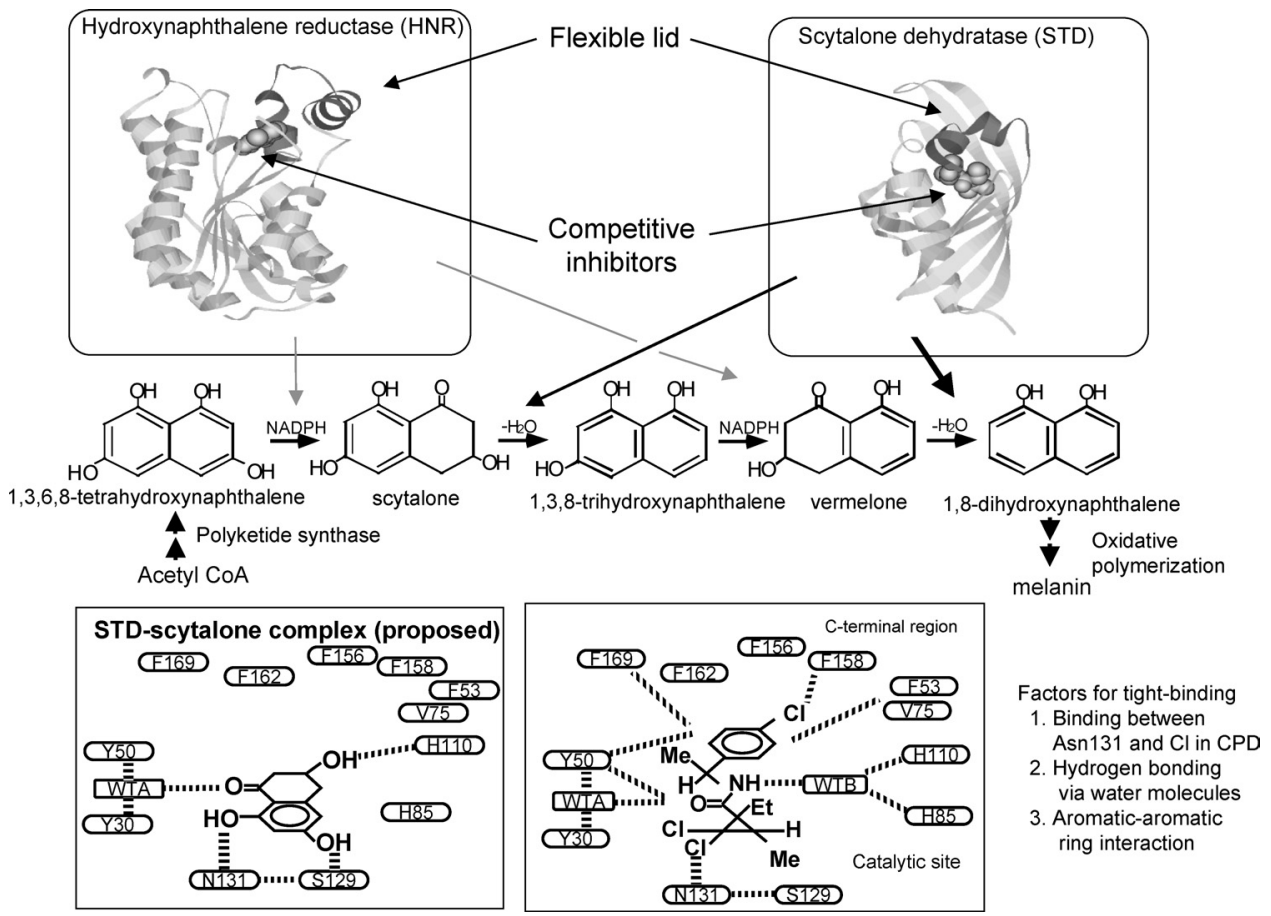

Fig. 1. Binding of inhibitors with key enzymes of melanin biosynthesis. Tight-binding between carpropamid and scytalone dehydratase. 

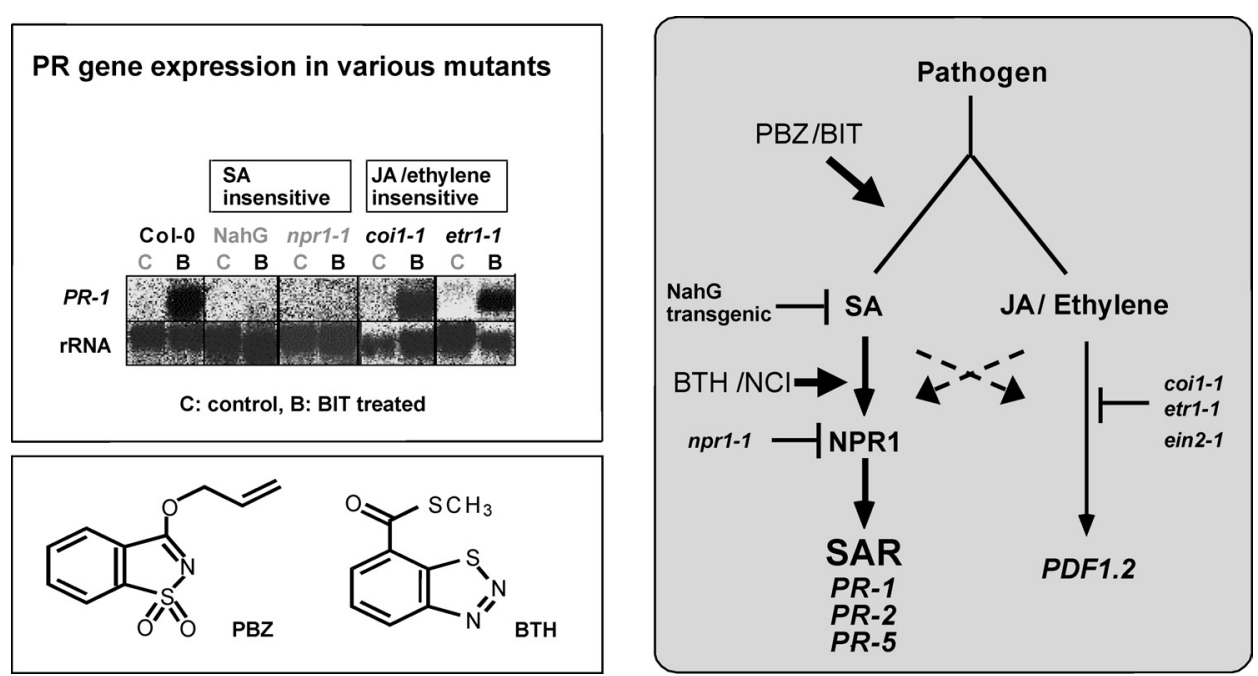

Fig. 2. Probenazole and BIT induce systemic acquired resistance (SAR).

cals in Japan. They are considered to have action mechanisms similar to carpropamid. Detailed analyses of the function of the catalytic region of STD may help in both understanding the mechanism of resistance to STD-inhibitors and designing more efficient chemicals.

\section{Anti-blast Chemicals That Induce Systemic Acquired Resistance in Plants}

Another attractive type of non-fungicidal chemicals, known as plant activators or priming effectors, induces systemic acquired resistance (SAR) in plants. Probenazole (PBZ) is a systemic agent which is quite effective against rice blast disease when applied to the root system. ${ }^{14)}$ The application of PBZ to rice plants was shown to induce or augment enzyme activities related to resistance in the invaded cells. The long lasting activity of PBZ was attributed to this host mediated defensive action. Acibenzolar- $S$-methyl (BTH) is also known to induce SAR in plants. ${ }^{15)}$ However, it was found that they have different sites of action; PBZ and its active metabolite (1,2-benzisothiazole-1,1-dioxide; BIT) act in the step prior to the biosynthesis of salicylic acid, whereas BTH induces SAR by acting downstream of salicylic acid ${ }^{16,17)}$ as shown in Fig. 2. Tiadinil, another plant activator, was recently registered as an anti-blast chemical, ${ }^{18)}$ and its action mechanism was reported to be similar to that of PBZ, BTH and other SAR inducers, e.g., $\mathrm{N}$-cyanomethyl-2-chloroisonicotinamide (NCI) and 3chloro-1-methyl-1 $H$-pyrazole-5-carboxylic acid. ${ }^{19)}$ The binding of these plant activators by still unknown receptors may induce defense-related reactions in plants through a specific signal cascade involving $\mathrm{G}$ proteins. ${ }^{20)}$

Figure 3 shows "sales of blast fungicides in Japan", which indicate that the non-fungicidal plant activator probenazole, and melanin biosynthesis inhibitors such as fthalide, tricyclazole, pyroquilon, and carpropamid are the main fungicides used to control blast disease in Japan.

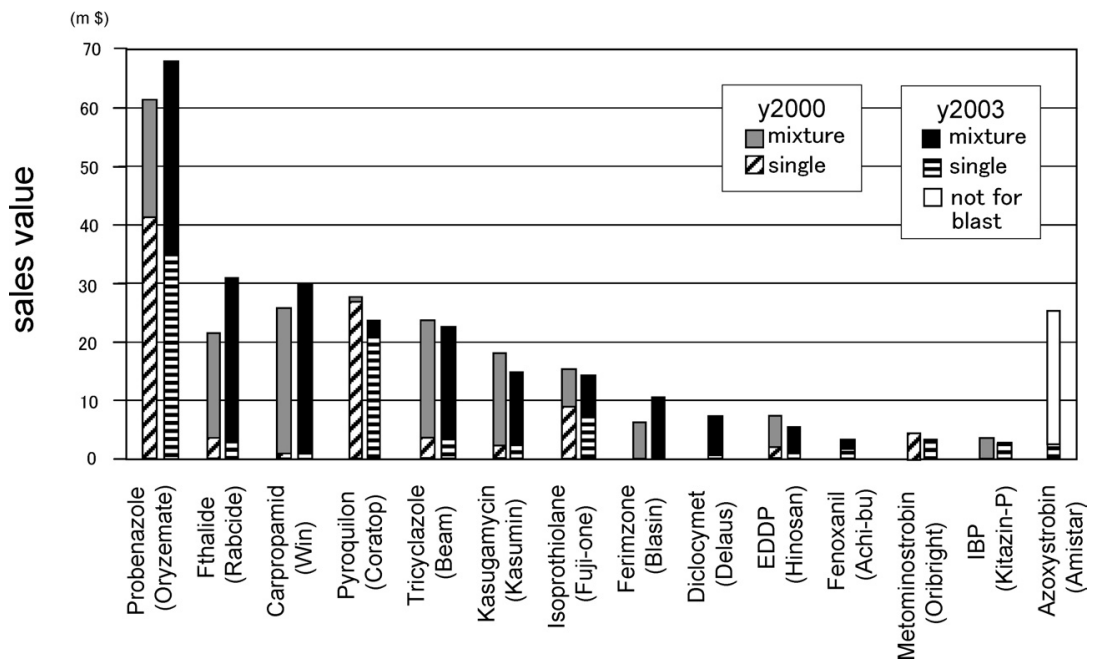

Fig. 3. Sales of major blast fungicides in Japan. 
Intermembrane space

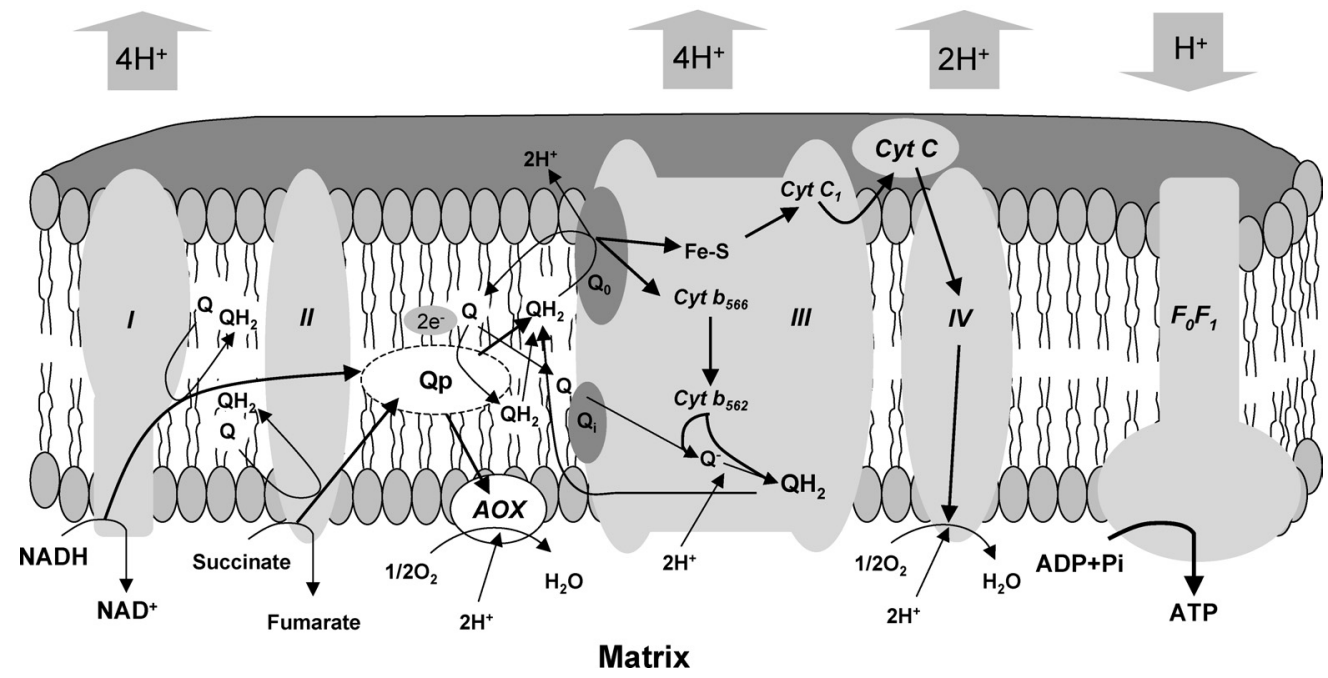

Fig. 4. Electron transport system in fungal mitochondria.

\section{FUNGICIDES ACTING ON RESPIRATORY CHAIN OF FUNGAL MITOCHONDRIA}

Mitochondrial respiration provides the energy needed for fungal disease development by linking NADH oxidation and coupled proton translocation with ATP synthesis. In fungi, the 'core' respiratory pathway involves three proton translocating complexes (I, III and IV), which are linked by ubiquinone and cytochrome $c$ as mobile electron carriers (Fig. 4). The function of complex III involves a cytochrome $b$ with two ubiquinone-binding sites, denoted Qo and Qi.

Strobilurins were isolated as secondary metabolites from species of Basidiomycotina and their methoxyacrylate derivatives proved to be quite effective and potential broad-spectrum fungicides (Fig. 5). They were shown to specifically block electron flow at the cytochrome $b c_{1}$ segment in complex III of the fungal mitochondrial respiratory chain, at either Qo (QoIs: Quinone outside inhibitors) or Qi (e.g., cyazofamid). These two sites of action can be bypassed by a cyanide insensitive alternative oxidase (AOX), creating a possible mechanism of resistance. However, if the electron flow is blocked at the cytochrome $b c_{1}$ segment and AOX accepts electrons directly from reduced ubiquinone, with protons being translocated solely by complex I, there will be only $4 / 10$ of the normal efficiency for ATP production in fungi. Metominostrobin belongs to the methoxyacrylate fungicides and inhibits respiration by blocking electron flux at Qo site in complex III. ${ }^{21)}$ The target pathogen, $M$. oryzae, induces cyanide-resistant AOX respiration when the cytochrome-mediated pathway was blocked by the chemical. Superoxide anion is considered to be involved in the metominostrobin-dependent induction of cyanide-resistant respiration. Flavonoids contained in plants, however, have an ability to scavenge the superoxide anion generated in pathogen cells and thus interfere with the metominostrobin-dependent induction of cyanide-resistant respiration. Consequently, metominostrobin can control the rice blast effectively in conjunction with rice plant components.

High levels of resistance to QoI fungicides have been found since 2000 in Europe and the resistance significantly increased in 2003. ${ }^{22)}$ The resistance factors between sensitive and resistant individuals were found to be more than 100 in Mycosphaerella graminicola (anamorph Septoria tritici), the pathogen of speckled leaf blotch of wheat. Interestingly, however, even when infected by resistant mutants, QoIs are believed to have a greening effect which brings about high yields with good quality possibly by keeping the leaves green up to the matured stage of the crop. ${ }^{23)}$ The control of Plasmopara viticola, the downy mildew pathogen of grapevine, and of Venturia inaequalis, the apple scab pathogen, requires intensive chemical spraying and recently resistant mutants have emerged. The exchange of glycine with alanine, G143A, at the Qo site of cytochrome $b$ is the major mechanism of resistance with a very high correlation to the resistance phenotype. FRAC recommends that QoI fungicides should be used preventatively and in mixtures or in alternation with effective partners of a different cross resistance group, and to limit the number of applications per season.

Cyazofamid, a novel class of fungicide (phenylimidazole), was discovered to have specific activity against Oomycete diseases such as late blight on potatoes and downy mildew on grapevines. ${ }^{24)}$ It was found to block electron transfer in the mitochondrial cytochrome $b c_{1}$ complex in the pathogens but the binding site of cyazofamid is at Qi of complex III and therefore it has a different site of action from other chemicals in Fig. 5. The highly specific activity of cyazofamid may be due to the difference in amino acid sequence and 3-D structure at the target Qi site in Oomycetes and Plasmodiophoromycete from those in other fungi, plants and animals. 

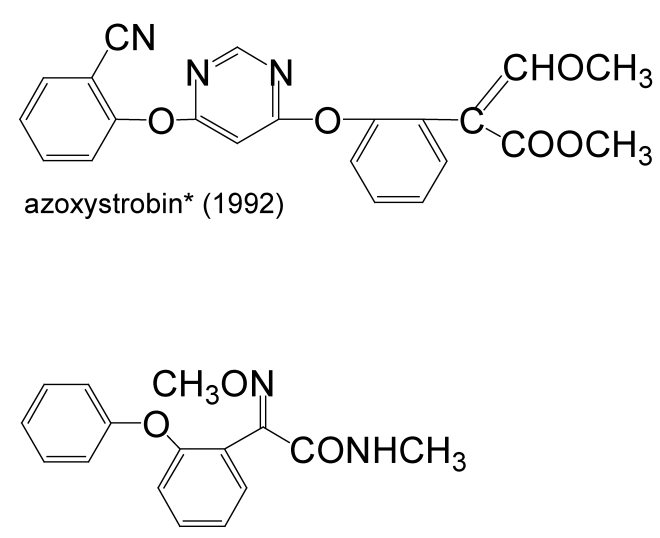

metominostrobin*(1993)<smiles>CO/C=C(/C(=O)OC)c1ccccc1COc1cccc(C(F)(F)F)n1</smiles>

picoxystrobin (2000)<smiles>CNC(=O)/C(=N\OC)c1ccccc1COc1cc(C)ccc1C</smiles>

dimoxystrobin (2001)

orysastrobin (2002)

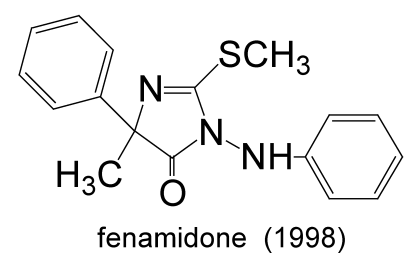<smiles>CO/N=C(/C1=NOCCO1)c1ccccc1Oc1ncnc(Oc2ccccc2Cl)c1F</smiles>

fluoxastrobin (2002)
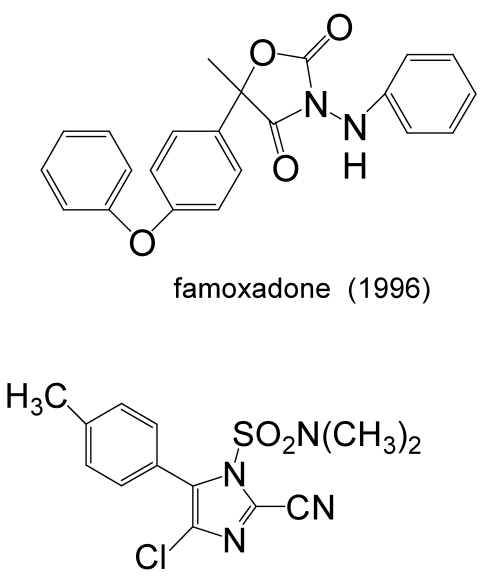

cyazofamid*(1998)

Fig. 5. Antifungal chemicals acting on complex III in the fungal respiratory chain.

* Registered in Japan, ${ }^{\dagger}$ Famoxadone and fenamidone are not strobilurin derivatives but inhibit Qo site. Cyazofamid is a Qi site inhibitor. 


\section{MODE OF ACTION OF DICARBOXIMIDE FUNGI- CIDES ON HISTIDINE KINASE SIGNAL PATHWAY}

1. Molecular Basis of Dicarboximide Resistance in Filamentous Fungi

Dicarboximide fungicides, iprodione and procymidone, have been applied to various crops and vegetables to protect against Botrytis cinerea, Monilinia spp., and Sclerotinia spp. $^{25)}$ However, Botrytis isolates resistant to dicarboximides have emerged after their extensive use, resulting in the reduction of fungicidal efficacy. In spite of many years of investigation, the mode of action and mechanisms of resistance to dicarboximides remain unclear, ${ }^{26)}$ but recent progress has revealed that dicarboximides interfere with the osmotic signal transduction pathway consisting of histidine kinase and MAP kinase cascades.

In response to osmotic pressure, fungi accumulate glycerol within the cells to increase internal turgor pressure. Dicarboximides and phenylpyrroles also stimulate glycerol synthesis in sensitive fungi, such as Neurospora crassa and $B$. cinerea. ${ }^{27)}$ Dicarboximide-resistant mutants obtained in the laboratory often showed abnormal osmotic sensitivity. In $N$. crassa, four osmotic-sensitive mutants, os- $1, o s-2, o s-4$, and $o s-5$, are resistant to dicarboximides and phenylpyrroles. Glycerol synthesis was not induced by the fungicides in the highly resistant os mutants. ${ }^{28,29)}$ The Neurospora os- 1 gene encodes a two-component histidine kinase similar to the yeast osmosensor $\operatorname{Snn} 1 \mathrm{p}^{30,31)}$ The osmotic regulation mediated by histidine kinase $\operatorname{Sln} 1 \mathrm{p}$ has been well characterized as a high osmolarity glycerol (HOG) pathway in Saccharomyces cerevisiae. $^{32)}$ Both histidine kinases, Neurospora Os1p and Saccharomyces $\operatorname{Sin} 1 \mathrm{p}$, are hybrid kinase which has a sensor region, a histidine kinase catalytic domain, and a response regulator domain. While the kinase and the response regulator modules of Os1p are highly conserved, the N-terminal sensor region of Os1p is quite different from that of Sln1p. Neurospora Os1p is considered to be a cytoplasmic protein with six repeats of about 90 amino acids in the N-terminal sensor region, whereas $\operatorname{Sin} 1 \mathrm{p}$ has potential membrane-spanning domains. A search of genome databases indicates that most filamentous fungi have the $o s-1$ family histidine kinase genes in their genome, while dicarboximide-insensitive $S$. cerevisiae and Schizosaccharomyces pombe do not. DNA sequencing of the $o s-1$ family genes has been carried out in many lab-resistant mutants of $N$. crassa ${ }^{33,34)}$ B. cinerea ${ }^{35)}$ and Cochliobolus heterostrophus. ${ }^{36)}$ Although these mutants showed different degrees of fungicide-resistance and osmotic sensitivity, most of them were found to differ in the amino acid repeat region of $o s-1$. More importantly, the $o s-1$ gene disruptants were highly resistant to fungicides in $N$. crassa. These results indicate that a fully functional Os1p is necessary for dicarboximide sensitivity.

In eukaryotic organisms, two-component histidine kinases often regulate a mitogen-activated protein (MAP) kinase path- way that leads to the regulation of a transcription factor. The osmosensor Sln $1 \mathrm{p}$ transmits signals to MAP kinase cascades composed of the SSK2/SSK22 MAPKK kinase, the PBS2 MAPK kinase and the HOG1 MAP kinase. Activation of the HOG1 MAP kinase induces the expression of genes responsible for osmotic adaptation, such as GDP1 and GPP2, for glycerol synthesis. ${ }^{32}$ To clarify the components regulated by the os- 1 histidine kinase in N. crassa, Neurospora NcSSK22 and $N C P B S 2$, similar to yeast $S S K 22$ and $P B S 2$, respectively, were cloned and characterized. ${ }^{37)}$ The wild-type NCSSK22 and $N c P B S 2$ genes were identical to $o s-4$ and $o s-5$, respectively. Furthermore, Zhang et al. revealed that the os-2 gene encoded the homologous HOG1 MAP kinase, and functionally complemented hogl mutants of $S$. cerevisiae. ${ }^{38)}$ These results suggest that the MAP kinase cascade consisting of os4 (MAPKK kinase), os-5 (MAPK kinase), and os-2 (MAP kinase) acts downstream of $o s-1$ histidine kinase (Fig. 6). Fungicides stimulate abnormal glycerol synthesis in the wildtype strain. Disruptants of these genes were sensitive to osmotic stress and resistant to dicarboximides and phenylpyrroles. These fungicides may inappropriately activate this signaling pathway and express their antifungal activity. Kojima et al. recently reported that fludioxonil treatment activated phosphorylation of MAP kinases related to $\mathrm{Neu}$ rospora Os $2 \mathrm{p}$ in Colletotrichum lagenarium, C. heterostrophus and B. cinerea. ${ }^{39)}$ These results strongly suggest that these fungicides act on the MAPK cascade in fungi. In yeast, constitutive activation of the HOG pathway caused by the disruption of negative regulators leads to lethality, unless the signaling is blocked by deletion of SSK2, PBS2, or HOG1. A similar mechanism may act in filamentous fungi exposed to fungicides. Because $o s-1$ is essential for antifungal activity and insensitive yeast do not have the $o s-1$ family histidine kinase gene, the $o s-1$ family histidine kinase can be proposed as a target protein of dicarboximides and phenylpyrroles. Pillonel et al., however, reported that a protein kinase (PK-III) possibly involved in osmoregulation was inhibited by phenylpyrroles but not by dicarboximides in $N$. crassa. ${ }^{27)}$ Thus the real targets of phenylpyrroles and dicarboximides have not yet been identified.

Signaling via cAMP may also play a role in fungicide resistance in some plant pathogens (Fig. 6). In basidiomycetes Ustilago maydis, two genes, $a d r l$ and $u b c 1$, which encode the catalytic subunit and the regulatory subunit of the U. maydis cAMP-dependent protein kinase (PKA), are implicated in resistance to the dicarboximide and aromatic hydrocarbon fungicides. ${ }^{40,41)}$ Gene mutations of the cAMP signaling pathway conferred fungicide resistance, although dicarboximide did not inhibit the activity of PKA. Interestingly, the mutants also showed osmotic sensitivity like Neurospora os mutants.

\section{Mutations Conferring Dicarboximide-resistance in the Field Isolates}

The spread of $B$. cinerea strains resistant to dicarboximides 

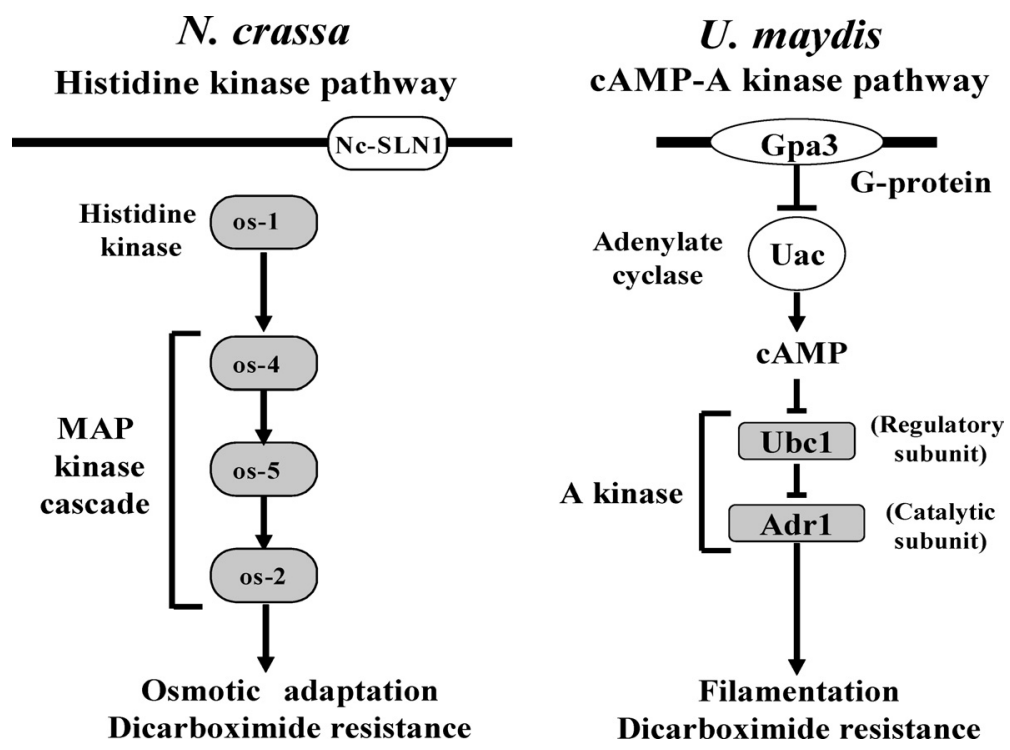

Fig. 6. Signal transduction pathway and dicarboximide resistance in N. crassa and U. maydis. The resistance genes are indicated by shadowed boxes.

has greatly reduced the usefulness of these chemicals in many countries. Like $N$. crassa os mutants, most lab-resistant mutants of $B$. cinerea acquire high resistance not only to dicarboximides but also to aromatic hydrocarbons and phenylpyrroles, and they are hypersensitive to osmotic stress. However, highly resistant strains of $B$. cinerea have seldom been obtained in the field. Only moderately resistant strains without osmotic-sensitive phenotypes have been recovered from the field, and they cause difficulties in disease control. Field isolates resistant to dicarboximides show cross-resistance to aromatic hydrocarbons but not to phenylpyrroles. Thus, fludioxonil controls gray mold effectively even in dicarboximide-resistant fields. The os 1 homolog, $B c O S 1$, was cloned and a single amino-acid substitution was found in field-resistant isolates of $B$. cinerea $^{42}$ ) The amino acid change (from isoleucine to serine at position 365 ; I365S) was located on the second of the tandem amino acid repeats of BcOs1p (Fig. 7). Recently, the same amino acid substitution has been identified in resistant strains by two groups. ${ }^{43,44)} \mathrm{Cui}$ et al. found other amino acid substitutions, I365N and I365R, in field resistant strains. The mutations conferring field resistance are limited to amino acid position 365 of BcOS1p in the $B$. cinerea field isolates. A possible explanation for the reduced variation in field-resistant mutations is that most muta- tions might affect the fitness of mutants and impose a selective disadvantage under field conditions. Resistance monitoring using molecular diagnosis suggests that resistant strains with $1365 \mathrm{~S}$ in the $\mathrm{BCOS} 1$ gene are major and spread widely in Japan, whereas some other mutations were found in strains collected from a certain area.

Dry et al. reported that two resistant isolates from Australian vine fields have mutations within the $o s-1$ family histidine kinase AaHK1 gene of Alternaria alternata. ${ }^{45)}$ Distinct from $B$. cinerea, A. alternata field isolates are resistant to both dicarboximides and phenylpyrroles, and their mutations cause immature termination in the sensor region of AaHK1p, although the distribution and fitness of these A. alternata fieldresistant strains remain unclear.

\section{CONCLUSION}

The exploitation and development of new chemicals have been becoming more and more difficult in recent years; cost effective studies on the toxicity of chemicals and residue analyses in crops, animals and the environment are required to ensure public health and preserve ecosystems. Further, pathogens resistant to new fungicides can emerge even with the use of non-fungicidal chemicals as was the case for MBID. Studies on the mode of action and mechanism of resist-

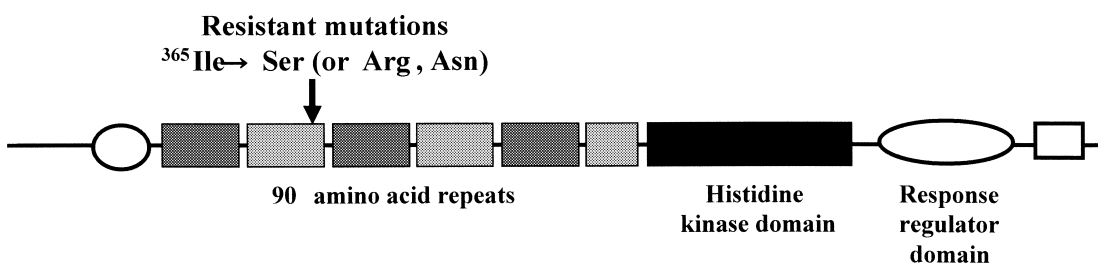

Fig. 7. $B c O S 1$ gene structure and amino acid substitutions conferring dicarboximide resistance. 
ance to fungicides are in many ways looking at the opposite sides of the same coin, and may suggest effective management strategies for the reliable control of diseases by minimizing or delaying the potential evolution of resistant mutants in the field.

\section{REFERENCES}

1) I. Yamaguchi and Y. Kubo: "Target Sites of Fungicide Action," ed. by W. Koeller, CRC Press, New York, pp. 101-114, 1992.

2) S. Kagabu and Y. Kurahashi: J. Pestic. Sci. 23, 145-147 (1998).

3) T. Mototyama, K. Imanishi, T. Kinbara, Y. Kurahashi and I. Yamaguchi: J. Pestic. Sci. 23, 58-61 (1998).

4) T. Motoyama, S. Kagabu, M. Matsuoka and I. Yamaguchi: $J$. Pestic. Sci. 27, 141-144 (2002).

5) M. Nakasako, T. Motoyama, Y. Kurahashi and I. Yamaguchi: Biochemistry 37, 9931-9939 (1998).

6) N. Okimoto, T. Nakamura, A. Suenaga, N. Futatsuji, Y. Hirano, I. Yamaguchi and T. Ebisuzaki: J. Am. Chem. Soc. 126, 13132 13139 (2004).

7) J. Yamaguchi, F. Kikuchi, K. Hiraya and K. So: Jpn. J. Phytopathol. 68, 261 (2001).

8) T. Shigyo, Y. Kuchii, Y. Araki and H. Sawada: "Rice Blast: Interaction with Rice and Control," ed. by S. Kawasaki, Kluwer Academic Publisher, Netherlands, pp. 281-287, 2004.

9) H. Sawada, M. Sugihara, M. Takagaki and K. Nagayama: Pest Manag. Sci. 60, 777-785 (2004).

10) M. Takagaki, K. Kaku, S. Watanabe, K. Kawai, T. Shimizu, H. Sawada, K. Kumakura and K. Nagayama: Pest Manag. Sci. 60, 921-926 (2004).

11) N. Yamada, T. Motoyama, M. Nakasako, S. Kagabu, T. Kudo and I. Yamaguchi: Biosci. Biotechnol. Biochem. 68, 615-621 (2004).

12) A. Manabe, K. Maeda, M. Enomoto, H. Takano, T. Katoh, Y. Yamada and Y. Oguri: J. Pestic. Sci. 27, 257-266 (2002).

13) A. Nishimura and I. Hino: Agrochem. Jpn. 13-15 (2002).

14) T. Watanabe, H. Igarashi, K. Matsumoto, K. Seki, S. Mase and Y. Sekizawa: J. Pestic. Sci. 2, 291 (1997).

15) I. Yamaguchi: "Fungicidal Activity," ed. by D. H. Hutson and J. Miyamoto, John Wiley \& Sons Ltd. pp. 193-219, 1998.

16) K. Yoshioka, H. Nakashita, D. Klessig and I. Yamaguchi: Plant J. 25, 149-157 (2001).

17) H. Nakashita, K. Yoshioka, M. Yasuda, T. Nitta, Y. Arai, S. Yoshida and I. Yamaguchi: Physiol. Mol. Plant Pathol. 61, 197203 (2002).

18) K. Umetani, F. Hakuno, A. Nishimura, Y. Yamamoto and T. Hirooka: Abst. Annu. Meeting Phytopathol. Soc. Jpn., 2003 (in Japanse).

19) M. Yasuda, H. Nakashita and S. Yoshida: J. Pestic. Sci. 29, 4649 (2004).

20) S. Komatsu, G. Yang, N. Hayashi, H. Kaku, K. Umemura and Y. Iwasaki: Plant Cell Environ. 27, 947-957 (2004).

21) M. Masuko, T. Kataoka, M. Ichinari and M. Niikawa: J. Pestic.
Sci. 26, 203-214 (2001).

22) H. Sierotzki, N. Kraus, P. Assemat, C. Stanger, S. Cleere, J. Windass and U. Gisi: Abst. 14th Int. Reinhardsbrunn Symposium, Reinhardsbrunn, April 25-29, 2004.

23) K. Grossmann, J. Kwiatkowski and G. Caspar: J. Plant Physiol. 154, 805-808 (1999).

24) T. Ohshima, T. Komyoji, S. Mitani, N. Matsuo and T. Nakajima: J. Pestic. Sci. 29, 136-138 (2004).

25) E. Pommer and G. Lorenz: "Modern Selective Fungicides," ed. by H. Lyr, Gustav Fischer Verlag, New York, pp. 99-118, 1995.

26) W. Edlich and H. Lyr: "Modern Selective Fungicides," ed. by H. Lyr, Gustav Fischer Verlag, New York, pp. 119-131, 1995.

27) C. Pillonel and T. Meyer: Pestic. Sci. 49, 229-236 (1997).

28) M. Fujimura, N. Ochiai, A. Ichiishi, R. Usami, K. Horikoshi and I. Yamaguchi: J. Pestic. Sci. 25, 31-36 (2000).

29) M. Fujimura, N. Ochiai, A. Ichiishi, R. Usami, K. Horikoshi and I. Yamaguchi: Pestic. Biochem. Physiol. 65, 125-133 (2000).

30) L. Alex, K. Borkovich and M. Simon: Proc. Natl. Acad. Sci. USA 93, 3416-3421 (1996).

31) M. Schumacher, C. Enderlin and C. Selitrennikoff: Curr. Microbiol. 34, 340-347 (1997).

32) S. Hohmann: Microbiol. Mol. Biol. Rev. 66, 300-372 (2002).

33) N. Ochiai, M. Fujimura, T. Motoyama, A. Ichiishi, R. Usami, K. Horikoshi and I. Yamaguchi: Pest Manag. Sci. 57, 437-442 (2001).

34) T. K. Miller, S. Renault and C. P. Selitrennikoff: Fungal Genet. Biol. 35, 147-155 (2002).

35) W. Cui, R. E. Beever, S. L. Parkes, P. L. Weeds and M. D. Templeton: Fungal Genet. Biol. 36, 187-198 (2002).

36) A. Yoshimi, M. Tsuda and C. Tanaka: Mol. Genet. Genomics 271, 228-236 (2004).

37) M. Fujimura, N. Ochiai, M. Oshima, T. Motoyama, A. Ichiishi, R. Usami, K. Horikoshi and I. Yamaguchi: Biosci. Biotechnol. Biochem. 67, 186-191 (2003).

38) Y. Zhang, R. Lamm, C. Pillonel, S. Lam and J. R. Xu: Appl. Environ. Microbiol. 68, 532-538 (2002).

39) K. Kojima, Y. Takano, A. Yoshimi, C. Tanaka, T. Kikuchi and T. Okuno: Mol. Microbiol. 53, 1785-1796 (2004).

40) A. B. Orth, M. Rzhetskaya, E. J. Pell and M. Tien: Appl. Environ. Microbiol. 61, 2341-2345 (1995).

41) M. A. Ramesh, R. D. Laidlaw, F. Durrenberger, A. B. Orth and J. W. Kronstad: Fungal Genet. Biol. 32, 183-193 (2001).

42) M. Oshima, M. Fujimura, S. Banno, C. Hashimoto, T. Motoyama, A. Ichiishi and I. Yamaguchi: Phytopathology 92, 7580 (2001).

43) P. Leroux, R. Fritz, D. Debieu, C. Albertini, C. Lanen, J. Bach, M. Gredt and F. Chapeland: Pest Manag. Sci. 58, 876-888 (2002).

44) W. Cui, R. E. Beever, S. L. Parkes and M. D. Templeton: Phytopathology 94, 1129-1135 (2004).

$45)$ I. B. Dry, K. H. Yuan and D. G. Hutton: Fungal Genet. Biol. 41, 102-108 (2004). 